\title{
Teaching Research on Assembly Language Course Based on Applied Talents Training
}

\author{
Mengqing Feng ${ }^{1,2, a}$ and Lijuan Qin ${ }^{1,2, b}$ \\ ${ }^{1}$ School of Information Engineering, Zhengzhou University of Industrial Technology, Zhengzhou \\ Henan 451150, PR China \\ ${ }^{2}$ Machine learning and Data researching Institute, Zhengzhou University of Industrial Technology, \\ Zhengzhou Henan 451150, PR China \\ a903901419@qq.com, b554259624@qq.com
}

Keywords: Applied talents; Information technology; Teaching model; Assembly language

\begin{abstract}
Assembly language plays an important role in the training of computer application talents. However, there are many problems in the current curriculum teaching, which can not be applied to the needs of personnel training. The paper focuses on the application of teaching talents and the aspects of curriculum goal setting, teaching content adjustment and updating, teaching method reform and curriculum assessment process, which highlights the application and practice of teaching, and has some reference for improving teaching effect significance.
\end{abstract}

\section{Introduction}

Application-oriented talents[1-3] mainly refers to the use of its scientific principles and knowledge, engaged in social production and life closely related to the work, directly to the community to create value of the high technical talent. Training mode, to "application" as the main purpose and characteristics of curriculum and teaching content system, emphasis on students' ability to apply technology training. With the development of information technology, the social demand for the application of computer professionals is gradually enlarged. How to train the computer application technology talents in line with the social needs has also become an important research topic in the computer teaching of the applied undergraduate colleges.

Assembly language[4-6] is a computer-related professional a compulsory basic course, is the computer composition principle, computer principle and interface technology, operating system courses such as the pilot course, in the entire professional curriculum system occupies a very important position. With the development of information technology[7-9], assembly language in the specific work of the scope of the application gradually reduced, making a lot of students produced assembly language is not important ideas. At the same time, compared to advanced programming language, assembly language is built on the hardware, portability is poor, the learning process need to know more hardware knowledge, no better integrated development environment, greatly reducing the student's interest in learning, teaching The effect is not ideal. But also affect the late related courses of learning. Therefore, it is necessary to analyze the present situation and existing problems of the assembly language course, and combine with the characteristics of the application of technical personnel training, to carry out the corresponding teaching reform, to enhance the teaching effect, to increase the training of computer application talents.

\section{Teaching Status and Problems}

Assembly Language is Closely Related to Hardware, and is Difficult to Learn. Assembly language is based on specific computer hardware, poor portability. At present, the domestic college assembly language course teaching is still 80X86CPU series of computer as a teaching model to carry out teaching activities. The course introduces the hardware of the computer, the working mode of the X86CPU, the addressing mode, the instruction system and so on. On this basis, the teaching of assembly language grammar and programming skills can be carried out. Before learning the 
course, students have less hardware-related knowledge and theoretical system, and the learning of assembly language is often very abstract, and many concepts are difficult to understand, such as addressing, registers, address adders, and so on.

Focus on the Foundation, Student Interest is Insufficient. At present, many colleges and universities assembly language teaching is as a programming language to teach, pay attention to the realization of grammar and algorithm, the computer work process, principle and its application in reality is not enough attention. Assembly language is not like high-level language, which has a strong directness, students can not simply through the organization and programming to achieve a certain application. At the same time because of its own difficult to learn characteristics, resulting in many students began to understand, with the gradual loss of interest in learning, it is difficult to learn.

Teaching Methods Outdated. The teaching of the subject is carried out according to the teaching method of the basic theory. According to the arrangement of the book, a chapter of the traditional inculcation teaching method is used to teach. The knowledge points are relatively fragmented and seem boring and difficult to form a whole in the minds of the students Of the assembly language system. Coupled with the difficulty of the course itself, making the students interested in the content of nothing, the teaching effect is not ideal.

\section{Teaching Reform Measures}

Assembly language is a computer-related professional a professional basic course, in the entire discipline system has a very important position, in order to reform through the application of personnel training and the rapid development of information technology needs, need all-round reform[10].

Clear Teaching Objectives. Focus on the teaching of assembly language, deepen the understanding of the working principle of the computer. Compared with the research university, the training goal of the applied talents is clear, that is, the training of the technical talents with the innovative ability for the society. Most of the future work of students is based on high-level language, their future career rarely have the opportunity to directly with the assembly language. Therefore, we should focus on the teaching of assembly language, the working principle of the computer, programming and assembly language program running on the principle, rather than the assembly language itself, the grammar rules.

Design Teaching Order. Compared to high-level language, assembly language entry is relatively difficult, it takes more time, greater patience and better hardware knowledge to be able to successfully entry. Most of the tutorials in the teaching content of the arrangement, usually in accordance with the basic knowledge, addressing methods, instruction system, program format and programming, subroutine programming and DOS and BIOS interrupt call order to carry out teaching implementation. In the actual teaching process sometimes in order to take care of the progress of teaching, pre-basic knowledge part of the teaching time is relatively small, which greatly increased the difficulty of the course, the enthusiasm of students to learn has a very big blow, is not conducive to teaching effect Ascension.

Therefore, many of the assembly language need to memorize the assembly instructions, according to the function of the dispersion, its learning is dispersed to the various chapters to go, so to reduce the short-term memory tasks, simple instructions arranged to the previous chapter, the complex instructions To the following chapters, such as add, sub and other simple instructions to the second chapter to learn, and complex div and mul instructions are placed in the following chapters. In addition, in order to make up for the compilation of assembly language learning, clever design experiments, as far as possible the visualization of the results of the experiment to enhance the interest of students to learn.

Update the Teaching Content, Closely Related to Technological Development. Assembly language courses opened for decades, 64-bit hardware and software systems have been widely popular today, assembly language teaching content is still based on the 8086 16-bit machine teaching content. Of course, these content also has some advantages, compared with 64-bit or 32-bit 
hardware and software systems, more simple, direct and easy to understand, making students learn and understand it easier. But should also be updated, the 32-bit assembly instructions and program design to sort out and streamline, and into the course of teaching, students can make people understand their daily use and familiar operating system operating details, thereby increasing Students interested in learning, for the latter are interested in hardware-driven development and virus analysis and other applications to lay the foundation for the work.

The Use of Advanced Teaching Methods and Means. The characteristics of the assembly language determine the effect of conventional inculcation teaching is not very good, and because the students now thinking ability and learning ability, but self-management ability is relatively weak, it should be integrated these factors, the use of a variety of teaching methods, So that students as much as possible in the classroom to learn the knowledge to understand, master.

Basic Concepts Teaching. The basics of the course mainly include the relevant concepts, definitions and grammatical rules, which do not involve complex algorithms, but the content itself must be able to remember, understand and understand clearly. They are the cornerstone of the course, the content is relatively simple, focus should be on the memory and understanding, it is appropriate to use the level of theoretical understanding and analysis of the way to carry out teaching. In the implementation of teaching, we should emphasize the understanding of content, through repeated repetitive training to achieve the intended teaching objectives.

Programming Teaching. The program design part is more flexible than the basic concept part, which focuses on the understanding of the characteristics of the program language and combines the corresponding algorithm ideas to achieve flexible programming. This part of the content of teaching, focusing on the understanding of language features, programming design and training methods of design training. This part of the content of teaching the implementation process, to combine a variety of teaching methods, such as project-driven teaching method, reverse thinking teaching method, divergent thinking teaching method to carry out teaching activities, and pay more attention to experimental teaching, through experimental activities, strengthen the theory of awareness And understanding, to the theory and practice of mutual confirmation of mutual promotion of benign interaction.

The use of Advanced Teaching Methods. Should use a variety of teaching methods, abandon the traditional interactive weak book teaching. Through the multimedia courseware, online learning website and simulation software, to strengthen the visualization of teaching content, understanding of the concrete and vivid, easy to learn and interactive process of diversification, making the traditional linear teaching into a multi-channel, multi-way Comprehensive teaching, so as to further enhance the convenience of knowledge acquisition, teaching interaction timeliness.

Improve the Assessment Objectives and Methods. The cultivation of applied computer talents emphasizes the application skills of talents, so the goal of the course should be designed around the goal of personnel training, and support the training objectives from the assessment objectives and assessment methods. Assessment methods must pay attention to the practice of talent hands practical training, the traditional examination paper examination methods, into a pay attention to normal, pay attention to practice usually with the final exam combination of assessment methods, highlighting the experimental assessment in the entire curriculum assessment of the status and Role, and after the end of each experiment are assessed to reduce the proportion of experimental report assessment results, highlighting the status of the assessment.

\section{Conclusion}

"Assembly language" as the application of computer-related professional professional courses, its importance in the curriculum system is self-evident, but as a traditional computer professional basic course, in the application of personnel training course teaching process is facing a new Challenges, such as obsolescence, backward teaching methods, unclear curriculum goals, and so on. Therefore, the need for curriculum reform to make it meet the needs of computer application-oriented personnel training. This paper analyzes the problems of the application of computer talents and the problems in the current teaching process, from the teaching objectives, teaching content, teaching 
methods and curriculum assessment and other aspects of reform. To study the teaching content, reform teaching methods and assessment objectives, pay attention to practical teaching, give full play to the enthusiasm of students in learning basic skills at the same time, but also to improve the students' Creative Thinking.

\section{References}

[1] Zeng X B. Deeping Experiment and Practice Teaching Reform and Improving the Cultivation Quality of Application-oriented Talents(Continued)[J]. Research \& Exploration in Laboratory, 2010.

[2] LU Ye, LIU Yong-liang, ZHANG Xiao-li. Research and Implementation of Java Curriculum Group for Application-oriented Talents Training $[\mathrm{J}]$. Research and Exploration in Laboratory, 2017.

[3] Chen J, Chen S. On the relationship between observance and innovation education in forging application-oriented talents[J]. Journal of Fujian University of Technology, 2014, 23(1):67-72.

[4] Miller F P, Vandome A F, Mcbrewster J. Assembly Language[M]. Alphascript Publishing, 2010.

[5] Xi H, Harper R. A dependently typed assembly language[C]// ACM Sigplan International Conference on Functional Programming. ACM, 2017:169-180.

[6] Vollmar K, Sanderson P. MARS:an education-oriented MIPS assembly language simulator[C]// Sigcse Technical Symposium on Computer Science Education. ACM, 2017:239-243.

[7] Smith, Shannon D.|Caruso, Judith Borreson. The ECAR Study of Undergraduate Students and Information Technology, 2010. Key Findings.[J]. Educause, 2010, 9(11):1297-1306..

[8] Nausheen Nizami, Narayan Prasad. Global Information Economy and Information Technology[M]// Decent Work: Concept, Theory and Measurement. Springer Singapore, 2017.

[9] King S, Cataldiroberts E, Wentz E. Meeting at the crossroads: collaboration between information technology departments and health sciences libraries[J]. Journal of the Medical Library Association Jmla, 2017, 105(1):27-33.

[10]Zhuang J L, Yang B. Teaching-Reform Measures for Development of Industrial-Type Software Technology Professionals[J]. Theory \& Practice of Education, 2007. 